DOI: $10.19195 / 0137-1169.38 .2$

\author{
GABRIELA DUDEK-WALIGÓRA \\ ORCID: 0000-0001-7951-8870 \\ Uniwersytet Jagielloński w Krakowie, Польша
}

\title{
Вопросно-ответный ход в российском политическом дискурсе*
}

Язык политиков - это очень интересный и актуальный объект исследований разных научных дисциплин во всем мире. Данная статья посвящена анализу вопросно-ответного хода в политическом дискурсе современной России. Политический дискурс, как и сам дискурс, - это многозначное понятие. В настоящей статье мы принимаем положение, выдвинутое В. И. Карасиком, который рассматривает политический дискурс как «коммуникативную практику, целью которой является борьба за власть» (Карасик 2010:67).

Тем самым, если политический дискурс ограничивается борьбой за власть, центральное место в нем занимают высказывания политиков, которым надо подвергаться процедуре избрания в выборах, чтобы активно участвовать в политической жизни страны ${ }^{1}$.

Следует также привести дефиницию ключевого термина данного исследования. Согласно И. Н. Кузнецову, вопросно-ответный ход является риторическим приемом, в котором говорящий задает вопрос (нередко фундаментальный), побуждая слушателей к размышлению, и формулирует свой ответ на него (Кузнецов 2004:207)2 . Е. С. Грищева, Е. В. Кобец, И. В. Пекарская и Е. А. Шпомер в своей дефиниции также акцентируют внимание на функ-

\footnotetext{
* Настоящая статья представляет собой расширенную версию доклада, который был прочитан на научной конференции „Россия в диалоге культур II. Литература, язык, культура” в Торуни (17-18 ноября 2017).

${ }^{1}$ Ср.: „Русский политический дискурс - это осуществляемый на русском языке речевой акт, сопровождающий политическое действие в определенной институциональной обстановке" (Гаврилова 2011:12).

2 В научной литературе вопросно-ответный ход называется также гипофорой и определяется как специфический вид риторического вопроса, где ответ предлагает сам говорящий (Москвин 2008:464).
} 
ции рассматриваемого явления: «Вопросно-ответный ход - употребление в речи вопроса и ответа на него как фигуры речи, задерживающей внимание» (Грищева и др. 2012:265).

Таким образом, вопросно-ответный ход выступает, когда оратор задает вопрос аудитории и сразу сам отвечает на него. Основные задачи данного приема заключаются в том, чтобы сосредоточить внимание на важных проблемах и побудить слушателей к размышлению.

Вопросы и ответы на них играют существенную роль в политическом дискурсе, особенно в процессе аргументации. «Вопросы служат специфическим видом доводов и могут применяться для выяснения, сомнения в истинности, уточнения информации, характеристики используемых в аргументации средств. С помощью вопросов могут формулироваться познавательные, проблемные ситуации, и, наконец, вопросы могут использоваться как тактические приемы и разного рода уловки» (Кузнецов 2004:272) . $^{3}$

Перед политическими деятелями стоит задача убедить избирателей и привлечь их на свою сторону (Герасименко 1998:22) 4 , поэтому вопросно-ответный ход применяется в политических текстах как средство речевого воздействия, то есть «воздействия человека на другого человека или группу лиц при помощи речи» (Стернин 2001:51). Цель данной статьи - подробно описать, как вопросно-ответный ход воздействует на слушателей в политическом дискурсе.

Материалом для анализа послужили тексты официальных, публичных высказываний современных российских политиков - Владимира Владимировича Путина, Дмитрия Анатольевича Медведева, Владимира Вольфовича Жириновского и Геннадия Андреевича Зюганова ${ }^{5}$. Напомним, что в настоящее время Путин является президентом России, Медведев занимает должность председателя Правительства Российской Федерации, Жириновский это руководитель фракции Либерально-демократической партии России в Государственной думе, Зюганов в свою очередь - это лидер Коммунистической партии Российской Федерации.

\footnotetext{
3 Ср.: «Аргументативные функции в максимальной степени присущи риторическому вопросу. Будучи имплицитным выражением отрицания или утверждения, риторический вопрос выступает в качестве маркера дискурсной ремы - отправной точки в цепочке рассуждений, средства постановки актуальной проблемы и ее прагматической фокусировки» (Шейгал 2004:206).

4 Многие исследователи подчеркивают роль убеждения в политическом дискурсе: «В многоплановом процессе, которым представлены акты политической коммуникации, помимо информативной функции, реализуется воздействующая, так как основная задача политика убедить адресата в правоте своей позиции и получить поддержку или желаемую реакцию. Таким образом, цель политического дискурса - не описание (не референция), а убеждение, т. е. пробуждение в адресате таких намерений, которые побудят его к правильному действию» (Муслех 2018:87).

5 Источники эмпирического материала представлены в библиографии.
} 
При помощи вопросно-ответного хода, как было уже замечено, политики прежде всего побуждают слушателей к размышлению. Рассмотрим примеры:

- Аутсорсинг, мы пришли к аутсорсингу, что это такое, все не по-русски. Население не готово к финансовым переменам, население финансово не образовано. Вы уже 25 лет навязываете ему английские термины. Что вы по-русски не можете говорить, падение экономики. Кризис как по-русски? Перегиб. Перегнули палку. Все поломалось. То есть товаров больше, чем покупателей. Никто не покупает, кризис. Почему кризис? Я произвел много товаров, вы не покупаете, я не могу вернуть кредит, я не могу заплатить транспортникам за доставку груза. Я не могу платить продавцам всем моим. Все, наступил кризис (Выступление В. В. Жириновского перед партийным активом ЛДПР по вопросу предстоящих выборов в МСУ в 2017-м году и выборов Президента России в 2018-м году, 5 июня 2017 года);

- Главная проблема в области безопасности сегодня какая? Терроризм. В Европе взрывают, в Париже взрывают, в России взрывают, в Бельгии взрывают, война идет на Ближнем Востоке - вот о чем надо думать, а мы все рассуждаем о том, какие угрозы Россия создает (Интервью В. В. Путина французской газете Le Figaro, 31 мая 2017 года); - Ведь что такое партия? Это люди. Это граждане нашей страны, которые живут в самых разных ее частях - в Москве, в Петербурге, здесь, в Северной Осетии, в других местах. И чем сильна наша партия? Этими людьми. Если люди ответственно трудятся, хорошо работают на разных должностях, тогда и наша партия сильна (Встреча Д. А. Медведева с победителями предварительного голосования партии «Единая Россия» в Северной Осетии, 13 июня 2017 года);

- Опыт цзарской России сто лет назад научил, что невозможно эффективно противостоять внешнему противнику, когда страну разрывают внутренние противоречия. Однако, что бы ни вещало руководство страны, но за прошедший год жить стало лучше только лишь олигархам: 26 богатейших олигархов страны добавили к своим капиталам ещзе 17 миллиардов долларов. А что же остальные? Около 22 миллионов наших сограждан выброшены за черту бедности (КПРФ Г. А. Зюганов поблагодарил избирателей, голосовавших за кандидатов КПРФ на выборах, 13 сентября 2017 года).

Данные примеры достаточно ярко иллюстрируют, что при помощи вопросов политики стремятся склонить адресатов к рефлексии. В приведенных фрагментах высказываний упомянутые политические деятели спрашивают о кризисе, проблеме в области безопасности, о партии и об условиях жиз- 
ни россиян. Как следует из процитированных высказываний, вопросы могут касаться различных сфер функционирования государства. Они служат установлению контакта с аудиторией и привлечению внимания к информации (Гаврилова 2004:193). Вопросно-ответный ход, по верному замечанию Е. И. Шейгал, позволяет включить слушателей в процесс рефлексии говорящего, а также позволяет наводить на желательный тип решения (Шейгал 2004:206). Тем самым, описываемый прием способствует большей эффективности и силе убеждения (там же). Слушатели могут принять изложенную политиком точку зрения как свою собственную, сформированную под его воздействием. «Вопрос направляет движение мысли, способствует актуализации неосознаваемого (эксплицирует невербализованное знание), побуждает к действию» (Демина 2014:178).

Применение политиками приема вопросно-ответного хода улушает понимание текста (Гаврилова 2004:192). Сравним примеры высказываний политиков:

- Важно, что российская экономика обретает новое качество, которого не было еще год назад. Что это такое - новое качество? О чем мы говорим? Во-первых, динамика. Динамика опирается на расширение внутреннего спроса, увеличение и потребления, и инвестициий (В. В. Путин, Инвестиционный форум «Россия зовет!», 24 октября 2017 года);

- Для любого депутата, депутата любого уровня, наверное, очень важной миссией является участие в подготовке бюджета. Потому что каким образом может депутат помочь гражданам, которые его выбрали? Правильно определив приоритеты. Что такое государственные приоритеты? Это в значительной степени ресурсы, включая деньги. Деньги, естественно, у нас функционируют в рамках бюдже$m a$ (Д. А. Медведев, Встреча с активом партии «Единая Россия» Сахалинской области, 23 августа 2017 года);

- Смотрю, куда деньги деваются? Деньги в основном присваивает олигархия. За прошльй год она увеличила свои доходы на 100 миллиардов, а за все эти годы выкачала из страны 61 триллион рублей (Г. А. Зюганов, Бюджет по-прежнему обслуживает богатых и унижает всех остальных, предваряя пленарное заседание Государственной Думы, перед журналистами выступил Председатель ЦК КПРФ, 27 октября 2017 года);

- Никто не оспаривает то хорошее, что происходило в истории нашей страны и других стран. Но мы должны правильно определить причиныл: почему что-то стало плохим? Потому что, если мы не выясним этого, мы не сможем двигаться вперед. Как наши граждане оказались за рубежсм? Были суровые времена, люди бежали от репрессий Ивана Грозного, Петра I, Александра II и так далее, от всех режимов бежали, но это были единицы (Выступление В. В. Жириновского на 
парламентских слушаниях Комитета Государственной Думы РФ по делам СНГ, евразийской интеграции и связям с соотечественниками, 20 марта 2017 года).

В приведенных примерах российские политики высказались на тему экономики, бюджета и истории России. Вопросы и ответы на них в указанных выступлениях позволяют выделить важные фразы, сосредоточить на них внимание слушателей и облегчить понимание текста. Нужно подчеркнуть, что вопросно-ответный ход также придает выступлениям динамичность (Гаврилова 2004:192-193).

Используя рассматриваемый прием, политический лидер создает впечатление, что он знает проблемы государства и общества, а также что может их решить. Посмотрим примеры:

- Я был в Киргизии. Спрашиваю: сколько послов знали киргизский язык? Ни один. Ну как ты можешь тогда работать в стране? Если человек не знает язык, - значит, он не знает культуру и обычаи. Ничего не знает. А тут чиновник, не специилист. Некуда направить. Вот открылась вакансия, отправили в Киргизию (Выступление В. В. Жириновского на парламентских слушаниях Комитета Государственной Думы РФ по делам СНГ, евразийской интеграции и связям с соотечественниками, 20 марта 2017 года);

- Как выташить из тупика образование и науку? Необходимо 6 принциниально пересмотреть объем финансирования образования и подчинить его задачам развития страны, остановить его деградацию (Статья Г. А. Зюганова «От чего уклонилась “прямая линия”» в газете «Советская Россия», 18 июня 2017 года);

- Если Вы внимательно слушали, что я вчера говорил, я говорил об укреплении ядерной триадь и в заключение сказал о том, что Российская Федерация сегодня сильнее любого потенциального - внимание! - агрессора. Это очень важно. Не случайно я об этом сказал. Что такое агрессор? Это тот, кто потенциально может напасть на Российскую Федерацию. Вот мы сильнее любого потенцииального агрессора, я могу и сейчас повторить это (Большая пресс-конференция В. В. Путина, 23 декабря 2016 года);

- В нашей работе по улучшению городской среды мы должны сосредоточиться на нескольких моментах. На каких? Первое - это долгосрочная государственная поддержка (Д. А. Медведев, Форум партии “Единая Россия” «Городская среда», 24 июля 2017 года).

\footnotetext{
${ }^{6}$ Ср.: «Функция лидера предполагает использование в выступлении модальности долженствования» (Гаврилова 2004:197).
} 
По мнению И. Н. Кузнецова, вопрос можно воспринимать как сорт требования, а ответ как предоставление затребуемой информации (Кузнецов 2004:273). В процитированных выступлениях российские политики заостряют внимание граждан на разных проблемах: на незнании языков в посольствах, падении культуры, на агрессоре и на городской среде. В ответах разъясняется точка зрения деятелей на методы преодоления этих трудностей. Как замечает Л. А. Демина, с помощью вопросов лучше всего можно выяснить, конкретизировать свою позицию и сформировать желательное решение (Демина 2014:183-184). В политическом дискурсе вопросно-ответный ход объясняет намерения государственных деятелей. Одновременно это прием, благодаря которому политик создает имидж компетентного, зрелого и надежного лидера. Ведь, согласно старинному правилу диалектики, кто задает вопросы, тот и доминирует (Демина 2014:178). Политики, несомненно, показывают, что будущее страны им небезразлично. В итоге высказывающиеся пробуют воздействовать на аудиторию, чтобы добиться ее поддержки.

Вопросно-ответный ход придает также эмоциональность выступлению. Верно подчеркивают В. Е. Чернявская и Е. Н. Молодыченко: «Эмоциональность подразумевает как выражение эмоций и чувств оратором по поводу некоторого положения дел, так и нацеленность языкового оформления речи на то, чтобы вызвать эмоциональный отклик со стороны адресата, “всколыхнуть” его чувства» (Чернявская, Молодыченко 2017:117). Вопросно-ответный ход повышает при этом выразительность речи. Рассмотрим примеры:

- Почему ошибки в истории нашего государства происходят со стороны руководства? Потому что руководство всегда наверху, оно не знает, что происходит внизу ${ }^{7}$ (Выступление В. В. Жириновского на собрании, посвященном празднованию 27-ой годовщины первого Съезда ЛДПР, 31 марта 2017 года);

- Смотрите, сейчас, совсем недавно, мы 8 были свидетелями нанесения ракетных ударов по Сирии Соединенными Штатами. Ну и как отреагировали союзники по НАТО? Все кивают, как китайские болванчики, не анализируя ничего, что происходит. Где доказательства применения сирийскими войсками химического оружия? Их нет. А нарушения международного права есть. Это очевидный факт. Без санкиии Со-

\footnotetext{
7 Метафоры очень часто встречаются в политической речи: «Популярность метафор в политической коммуникации и в конфронтационной риторике в частности объясняется и тем, что метафоры упрощают представление сложных политических явлений и делают их доступными для понимания среднестатистическим реципиентом» (Чернявская, Молодыченко 2017:128).

${ }^{8}$ Ср.: «Речевое поведение В. В. Путина показывает его стремление солидаризироваться с аудиторией, что выражается, в частности, в употреблении местоимения мы в именительном падеже и в формах косвенных падежей — нам, у нас в значении “я и вы”» (Паршина 2012:149).
} 
вета Безопасности ООН наносится удар по суверенной стране (Интервью В. В. Путина телерадиокомпании «Мир», 12 апреля 2017 года);

- Что является главным? Главным является исполнение всех обязательств, наказов, которые вы получили от наших граждан, избирателей. Это, мы с вами понимаем, самое сложное и в деятельности исполнительной власти, губернаторов, высших долэнностных лии субъектов Федераиии, и в деятельности депутатов. Поэтому единым днем голосования не завершается наша работа, а только начинается (Д. А. Медведев, Селекторное совещание с избирательными штабами региональных отделений партии «Единая Россия», 10 сентября 2017 года);

- За чей же счет будут покрываться их долги [компании «Роснефть»]? 3 а счет личного состояния олигархов? За счет доходов членов правления? ${ }^{9}$ Нет, они будут покрываться за счет государства и за счет граждан. Они будут восполняться за счет средств, изымаемых из давно прохудившегося народного кармана. Такой политике нужно положить конеи (Г. А. Зюганов, Время голосует за социализм, 28 августа 2017 года).

В вышеуказанных фрагментах выступлений речь идет об ошибках руководства, ударах по Сирии, о работе политиков и о долгах компании «Роснефть». Данные высказывания приобретают эмоционально-экспессивную окраску. Политики сосредоточиваются на отрицательных эмоциях. Только Д. А. Медведев в приведенном примере пытается настроить аудиторию положительно.

Собранный материал показал, что на эмоциональность речи влияют прежде всего такие языковые механизмы, как, конечно, вопросы и ответы, а также метафоры, разговорные выражения (тут выражение кивают, как китайские болванчики из интервью В. В. Путина) и повторы. Они усиливают коммуникативное воздействие речи. Следует добавить, что многими учеными эмоции трактуются как очень важное средство речевого воздействия: «Убеждение в политическом дискурсе связывается преимущественно с воздействием на эмоции и подсознание, а не на разум, логическое мышление. Особенно это характерно для общения политиков с населением, где суггестивный момент преобладает над рациональным, а успех коммуникации основан прежде всего на завоевании симпатии и доверия адресата» (Шейгал $2004: 77)^{10}$.

\footnotetext{
9 Надо заметить, что «повторы делают речь легкой, запоминающейся, так как придают ей определенный ритм» (Кузнецов 2004:205). Здесь выступает разновидность повторов, которая называется анафора. Это «единоначалие, повтор одних и тех же элементов в начале каждого параллельного ряда» (там же).

10 Подробнее на тему эмоций в политических текстах см. исследование: Дудэк 2012.
} 
Благодаря представленным примерам, можно убедительно констатировать, что вопросно-ответный ход помогает политикам воздействовать на общество. В результате анализа собранных текстов политического дискурса можно сделать вывод о том, что данный риторический прием служит для того, чтобы установить контакт с аудиторией, привлечь внимание к информации, придать выступлениям политиков динамичность, выразительность и, конечно, эмоциональность. Самое главное, однако, - это то, что вопросно-ответный ход наводит на желательный политическим деятелем тип решения предлагаемых для рассмотрения проблем. Языковой материал показал, что вопросно-ответный ход является активно использованным приемом в политическом дискурсе современной России.

\section{Библиография}

\section{Источники эмпирического материала}

Bol'šaâ press-konferenciâ V. V. Putina, 23 dekabrâ 2016 goda, http://kremlin.ru/events/president/ news/53573 (dostup 15.11.2019).

D. A. Medvedev, Forum partii «Edinaâ Rossiâ» «Gorodskaâ sreda», 24 iûlâ 2017 goda, http://damedvedev.ru/news/item/25552/ (dostup 15.11.2019).

D. A. Medvedev, Selektornoe soveŝanie s izbiratel'nymi štabami regional'nyh otdelenij partii «Edinaâ Rossiâ», 10 sentâbrâ 2017 goda, http://медведев.pф/news/item/25575/ (dostup 15.11.2019).

D. A. Medvedev, Vstreča s aktivom partii «Edinaâ Rossiâ» Sahalinskoj oblasti, 23 avgusta 2017 goda, http://медведев.pф/news/item/25574/ (dostup 15.11.2019).

G. A. ZûGANov, Bûdžet po-prežnemu obsluživaet bogatyh i unižaet vseh ostal'nyh, predvarââ plenarnoe zasedanie Gosudarstvennoj Dumy, pered žurnalistami vystupil Predsedatel' CK KPRF, 27 oktâbrâ 2017 goda, https://kprf.ru/party-live/cknews/170005.html (dostup 15.11.2019).

G. A. ZÛGANOv, Vremâ golosuet za socializm, 28 avgusta 2017 goda, https://kprf.ru/party-live/ cknews/168197.html (dostup 15.11.2019).

Interv'û V. V. Putina francuzskoj gazete Le Figaro, 31 maâ 2017 goda, http://kremlin.ru/events/ president/news/54638 (dostup 15.11.2019).

Interv'û V. V. Putina teleradiokompanii «Mir», 12 aprelâ 2017 goda, http://kremlin.ru/events/president/news/54271 (dostup 15.11.2019).

KPRF G. A. Zûganov poblagodaril izbiratelej, golosovavših za kandidatov KPRF na vyborah, 13 sentâbrâ 2017 goda, http://mkkprf.ru/17255-ga-zyuganov-spasibo-za-vashu-podderzhku. html (dostup 15.11.2019).

Stat'â G. A. Zûganova «Ot čego uklonilas' "prâmaâ liniâ"» v gazete "Sovetskaâ Rossiâ», 18 iûnâ 2017 goda, https://kprf.ru/party-live/cknews/166300.html (dostup 15.11.2019).

V. V. Putin, Investicionnyj forum «Rossiâ zovet!», 24 oktâbrâ 2017 goda, http://kremlin.ru/events/ president/news/55903 (dostup 15.11.2019).

Vstreča D. A. Medvedeva s pobeditelâmi predvaritel'nogo golosovaniâ partii «Edinaâ Rossiâ» v Severnoj Osetii, 13 iûnâ 2017 goda, http://медведев.pф/news/item/25537/ (dostup 15.11.2019).

Vystuplenie V. V. Žirinovskogo na parlamentskih slušaniâh Komiteta Gosudarstvennoj Dumy RF po delam SNG, evrazijskoj integracii i svâzâm s sootečestvennikami, 20 marta 2017 goda, https:// ldpr.ru/leader/speech/Speech_by_Vladimir_Zhirinovsky_March_20_2017/(dostup 15.11.2019). 
Vystuplenie V. V. Žirinovskogo na sobranii, posvâŝennom prazdnovaniû 27-oj godovŝiny pervogo S"ezda LDPR, 31 marta 2017 goda, https://ldpr.ru/leader/speech/Zhirinovskys_speech_at_the_ meeting_dedicated_to_the_27th_anniversary_of_the_first_LDPR_Congress_on_March_31_ 2017/ (dostup 15.11.2019).

Vystuplenie V. V. Žirinovskogo pered partijnym aktivom LDPR po voprosu predstoâsih vyborov v MSU v 2017-m godu i vyborov Prezidenta Rossii v 2018-m godu, 5 iûnâ 2017 goda, https://ldpr. ru/leader/speech/The_speech_of_Vladimir_Zhirinovsky_in_front_of_party_activists_of_the_ liberal_democratic_party_regarding_the_upcoming_elections_in_MSU_in_2017_the_year_ and the presidential_elections_in_Russia_in_2018_year_5_June_2017/ (dostup 15.11.2019).

Большая пресс-конференция В. В. Путина, 23 декабря 2016 года, http://kremlin.ru/events/president/news/53573 (доступ 15.11.2019).

В. В. Путин, Инвестиционный форум «Россия зовет!», 24 октября 2017 года, http://kremlin.ru/ events/president/news/55903 (доступ 15.11.2019).

Встреча Д. А. Медведева с победителями предварительного голосования партии «Единая Россия» в Северной Осетии, 13 июня 2017 года, http://медведев.pф/news/item/25537/ (доступ 15.11.2019).

Выступление В. В. Жириновского на собрании, посвященном празднованию 27-ой годовщины первого Съезда ЛДПР, 31 марта 2017 года, https://ldpr.ru/leader/speech/Zhirinovskys speech_at_the_meeting_dedicated_to_the_27th_anniversary_of_the_first_LDPR_Congress_ on_March_31_2017/ (доступ 15.11.2019).

Выступление В. В. Жириновского на парламентских слушаниях Комитета Государственной Думы РФ по делам СНГ, евразийской интеграции и связям с соотечественниками, 20 марта 2017 года, https://ldpr.ru/leader/speech/Speech_by_Vladimir_Zhirinovsky_March_20_2017/ (доступ 15.11.2019).

Выступление В. В. Жириновского перед партийным активом ЛДПР по вопросу предстоящих выборов в МСУ в 2017-м году и выборов Президента России в 2018-м году, 5 июня 2017 года, https://ldpr.ru/leader/speech/The_speech_of_Vladimir_Zhirinovsky_in_front_of_party_ activists_of_the_liberal_democratic_party_regarding_the_upcoming_elections_in_MSU_ in_2017_the _year_and_the_presidential_elections_in_Russia_in_2018_year_5_June_2017/ (доступ 15.11.2019).

Г. А. Зюганов, Бюджет по-прежнему обслуживает богатых и унижает всех остальных, предваряя пленарное заседание Государственной Думы, перед журналистами выступил Председатель ЦК КПРФ, 27 октября 2017 года, https://kprf.ru/party-live/cknews/170005.html (доступ 15.11.2019).

Г. А. Зюганов, Время голосует за социализм, 28 августа 2017 года, https://kprf.ru/party-live/ cknews/168197.html (dostup 15.11.2019).

Д. А. Медведев, Встреча с активом партии «Единая Россия» Сахалинской области, 23 августа 2017 года, http://медведев.pф/news/item/25574/ (dostup 15.11.2019).

Д. А. Медведев, Селекторное совещание с избирательными штабами региональных отделений партии «Единая Россия», 10 сентября 2017 года, http://медведев.pф/news/item/25575/ (dostup 15.11.2019).

Д. А. Медведев, Форум партии «Единая Россия» «Городская среда», 24 июля 2017 года

Интервью В. В. Путина телерадиокомпании «Мир», 12 апреля 2017 года, http://kremlin.ru/ events/president/news/54271 (dostup 15.11.2019).

Интервью В. В. Путина французской газете Le Figaro, 31 мая 2017 года, http://kremlin.ru/events/ president/news/54638 (dostup 15.11.2019).

КПРФ Г. А. Зюганов поблагодарил избирателей, голосовавших за кандидатов КПРФ на выбоpax, 13 сентября 2017 года, https://kprf.ru/party-live/cknews/170005.html (dostup 15.11.2019).

Статья Г. А. Зюганова «От чего уклонилась “прямая линия”» в газете «Советская Россия», 18 июня 2017 года, https://kprf.ru/party-live/cknews/166300.html (dostup 15.11.2019). 


\section{Научная литература}

Bogdanova-BeglarÂn Natal'â Viktorovna, 2016, Voprositel'nye konstrukcii v ustnoj spontannoj reči: adresnost', ritoričnost', idiomatičnost', v: Kommunikativnye Issledovaniâ 4 (10), s. 61-76.

ČERNÂVSKAÂ Valeriâ Evgen'evna / MoLODYČENKo Evgenij Nikolaevič, 2017, Rečevoe vozdejstvie $\mathrm{v}$ političeskom, reklamnom i internet-diskurse, Moskva.

Demina Larisa Anatol'evna, 2014, Teoriâ i praktika argumentacii. Učebnoe posobie, Moskva.

Dudèk Gabrièla, 2012, Rol' èmocij v političeskih tekstah, v: Russkij âzyk za rubežom 1, s. 65-71.

GavriLova Marina Vladimirovna, 2004, Kognitivnye i ritoričeskie osnovy prezidentskoj reči (na materiale vystuplenij V. V. Putina i B. N. El'cina), Sankt-Peterburg.

GaVRILOva Marina Vladimirovna, 2011, Analiz programm rossijskih političeskih partij načala XX i XXI vekov (lingvističeskij aspekt), Sankt-Peterburg.

GERASIMENKo Natal'â Arkad'evna, 1998, Informaciâ i fascinaciâ v političeskom diskurse (k voprosu o funkcionirovanii bisubstantivnyh predloženij), v: Sorokin U. A./Bazylev N. V. (red.), Političeskij diskurs v Rossii - 2. Materialy rabočego soveŝaniâ 29 marta 1998 goda, Moskva, s. 20-23.

Griŝeva Elena Sergeevna / Kobec Elena Valer'evna / PeKarskaÂ Irina Vladimirovna / Špomer Ekaterina Andreevna, 2012, Sovremennyj političeskij diskurs v kontekste kommunikativnoj i âzykovoj pragmatiki: monografiâ i sistemnyj slovar'-spravočnik «Âzyk politika», Abakan.

IsseRs Oksana Sergeevna, 2009, Rečevoe vozdejstvie. Učebnoe posobie, Moskva.

KARASIK Vladimir Il'ič, 2010, Igra po pravilam v političeskom diskurse o Rossii na Zapade, v: Čudinov A. P. (red.), Obraz Rossii v zarubežnom političeskom diskurse: stereotipy, mify i metafory. Materialy Meždunarodnoj naučnoj konferencii 13-17 sentâbrâ 2010, Ekaterinburg, s. 66-69.

KuZNECOv Igor' Nikolaevič, 2004, Ritorika ili oratorskoe iskusstvo, Moskva.

Moskvin Vasilij Pavlovič, 2008, Argumentativnaâ ritorika: teoretičeskij kurs dlâ filologov. Izd. 2-e, pererab. i dop., Rostov-na-Donu.

MusLeH Husam, 2018, Strategiâ ubeždeniâ v rečah palestinskogo lidera Âsira Arafata, v: Političeskaâ lingvistika 1 (67), s. 87-97.

PARŠINA Ol'ga Nikolaevna, 2012, Rossijskaâ političeskaâ reč'. Teoriâ i praktika, Moskva.

ŠEJGal Elena Iosifovna, 2004, Semiotika političeskogo diskursa, Moskva.

STERnIN Iosif Abramovič, 2001, Vvedenie v rečevoe vozdejstvie, Voronež.

БогДАНОВА-БЕГЛАРян Наталья Викторовна, 2016, Вопросительные конструкции в устной спонтанной речи: адресность, риторичность, идиоматичность, в: Коммуникативные Исследования 4 (10), с. 61-76.

ГАвриловА Марина Владимировна, 2004, Когнитивные и риторические основы президентской речи (на материале выступлений В. В. Путина и Б. Н. Ельцина), Санкт-Петербург.

ГАвРиловА Марина Владимировна, 2011, Анализ программ российских политических партий начала XX и XXI веков (лингвистический аспект), Санкт-Петербург.

ГерАсименко Наталья Аркадьевна, 1998, Информация и фасцинация в политическом дискурce (к вопросу о функционировании бисубстантивных предложений), в: Сорокин Ю. А./ Базылев Н. В. (ред.), Политический дискурс в России - 2. Материалы рабочего совещания 29 марта 1998 года, Москва, с. 20-23.

ГрищевА Елена Сергеевна / КоБЕц Елена Валерьевна / ПекАРскАя Ирина Владимировна / ШпомеР Екатерина Андреевна, 2012, Современный политический дискурс в контексте коммуникативной и языковой прагматики: монография и системный словарь-справочник «Язык политика», Абакан.

Демина Лариса Анатольевна, 2014, Теория и практика аргументации. Учебное пособие, Москва.

Дудэк Габриэла, 2012, Роль эмоций в политических текстах, в: Русский язык за рубежом 1, c. $65-71$. 
ИссеРС Оксана Сергеевна, 2009, Речевое воздействие. Учебное пособие, Москва.

КАРАСик Владимир Ильич, 2010, Игра по правилам в политическом дискурсе о России на Западе, в: Чудинов А. П. (ред.), Образ России в зарубежном политическом дискурсе: стереотипы, мифы и метафоры. Материалы Международной научной конференции 13-17 сентября 2010, Екатеринбург, с. 66-69.

Кузнецов Игорь Николаевич, 2004, Риторика или ораторское искусство, Москва.

Москвин Василий Павлович, 2008, Аргументативная риторика: теоретический курс для филологов. Изд. 2-е, перераб. и доп., Ростов-на-Дону.

Муслех Хусам, 2018, Стратегия убеждения в речах палестинского лидера Ясира Арафата, в: Политическая лингвистика 1 (67), с. 87-97.

ПАРшинА Ольга Николаевна, 2012, Российская политическая речь. Теория и практика, Москва.

СтеРнин Иосиф Абрамович, 2001, Введение в речевое воздействие, Воронеж.

Чернявская Валерия Евгеньевна / Молодыченко Евгений Николаевич, 2017, Речевое воздействие в политическом, рекламном и интернет-дискурсе, Москва.

ШейгАл Елена Иосифовна, 2004, Семиотика политического дискурса, Москва.

\section{The question and answer method in Russian political discourse}

The article presents one of the types of rhetorical mechanisms used in political discourse - the question and answer method. The question and answer method is a rhetorical device in which the speaker asks a question and formulates his answer to it. The material for research is based on the official public texts of utterances made by contemporary Russian politicians: Vladimir Vladimirovich Putin, Dmitry Anatolyevich Medvedev, Vladimir Volfovich Zhirinovsky and Gennady Andreyevich Zyuganov. Definitions of the question-answering method are provided and the main functions of this phenomenon are given. The analysis shows that the question-answering method helps politicians to persuade society. It can be concluded that this rhetorical device serves to establish contact with the audience, to draw attention to information, to make the speeches of politicians dynamic, expressive and emotional. The most important thing, however, is that the question-answering method leads to the type of solution proposed by the politician that is desirable for the consideration of problems. The linguistic material has shown that this is an actively used method in the political discourse of contemporary Russia.

Keywords: political linguistics, rhetoric, political discourse, political speeches. 